\title{
Determination of Correct Lighting Based on Fuzzy Logic Model to Reduce Electricity in the Workplace
}

\author{
Ph.D. Candidate Rahib Imamguluyev (Odlar Yurdu University, Azerbaijan)
}

\begin{abstract}
Today, awareness of electrical systems is almost one of our main needs. Reducing our energy consumption by ensuring energy efficiency in such a widely used system provides savings that will affect the economy and the life of energy sources, both economically and in terms of energy efficiency. The difference between electricity generation and the amount of electricity required in the last few years has been a cause for concern. In recent years, due to the increase in electricity prices, the steering committees of various organizations have begun to consider various ways to reduce electricity prices, and in this regard, attention should be paid to the basic lighting system. By applying healing methods or using new technologies without reducing production and switching to more efficient use of energy. Improving energy efficiency is more economical than investing in new energy sources. Energy saving in lighting is to provide good lighting conditions without compromising the quality of light. It is possible to achieve the same level of lighting with energy consumption, as good lighting will be provided by more efficient lighting elements. With efficient lighting, there will be less electricity consumption and eye health will be protected. This article discusses the application of a lighting system based on a fuzzy logic model to reduce electricity costs in offices.
\end{abstract}

\section{Introduction}

Lighting is an essential necessity in our daily lives and the most common type of energy used in lighting today is electrical energy. Efficiency is the ratio of the received light energy to the electricity consumed in the lighting systems operating with electrical energy.

Providing energy efficiency in lighting goes through small details. For example, incandescent lamps that we use in daily life use large amounts of electrical energy to convert most of this energy to heat energy, thereby emitting unnecessary energy by emitting heat. By replacing these lamps with fluorescent or LED lamps (Ağan, Y.,.2005) with less energy loss, we reduce energy consumption and provide efficiency in lighting energy.

In addition, savings in lighting systems can be achieved with energy management. Lighting systems can be provided by creating technology control systems based on GPRS, GSM or SCADA. In this way, energy savings can be achieved by eliminating dead time in lighting times.

Energy saving in lighting can be achieved by using high efficiency light sources instead of low efficiency light sources and by taking some simple measures. The important thing here is to show the necessary attention to the subject. Some of these measures can be listed as follows:

1. High efficient ones should be preferred when purchasing a lamp. Lamp selections should be made based on the highest lumen / watt ratio (efficiency factor).

2. Unused areas should not be illuminated.

3. Daylight should be used as much as possible.

4. Lighting fixtures should be periodically maintained. Dirty and dusty fixtures absorb some of the light and cause inefficient lighting.

5. Lamp light output should be used efficiently. Whether the lamp light output reaches the surfaces to be illuminated at the maximum rate is one of the most important factors affecting the efficiency of the lighting system.

6. Controlling lighting through timers, photocells or proximity sensors is important for energy savings.

7. Wall, ceiling and decoration materials should be selected as light as possible.

8. In sections where more light is needed, using a single high power lamp instead of many low power lamps provides more efficient lighting.

9. Care should be taken to use small powerful bulbs in stair lighting.

10. Decorative lamps send light in undesirable directions. Light-colored, transparent shade lampshades transmit light better.

11. Lamps should be turned off when leaving the room.

12. Table lamp should be used while working.

13. Fluorescent bulbs should be used instead of halogen and normal bulbs to prevent energy loss. Thus, $40 \%$ energy savings can be achieved.

14. The use of compact fluorescent lamps instead of incandescent lamps saves up to $80 \%$ energy (Çolak, N., 2003).

15. In road lighting, if high pressure sodium vapor lamps are used instead of high pressure mercury vapor lamps, approximately $60 \%$ savings are achieved at the same level of illumination. 
16. In garden and environmental lighting, if low pressure sodium vapor lamps are preferred instead of high pressure mercury vapor lamps, approximately $70 \%$ energy savings can be achieved at the same level of brightness (Daylighting Control, 2020).

\subsection{New Energy Economy}

With the transformation of energy, there is also an evolution in the energy economy.

Green economy is defined as the economy that aims to reduce environmental risks and ecological scarcity and aims at sustainable development without harming the environment. In the report published by the United Nations Environment Program (UNEP) in 2011, the concept of green economy is defined as "Policies aimed at reducing environmental risks and improving ecological wealth significantly by ensuring the welfare and social equality of humanity".

Looking at it, many environmental activists see capitalism as an enemy. While the debates are endless, we must admit that the economy and society are actually intertwined in today's capitalist world. In this period when society is slowly reorganizing and adopting environmental reforms, we cannot think of the economy as a natural consequence behind it. Ideas such as the 'green economy' are also proof that these two factors are actually parallel.

Energy economy, on the other hand, refers to the study of the supply and use of energy. This also includes the impact of energy consumption.

Many companies claim to have a green energy plan today. Actually this has almost become a trend. However, we can say that technology is not progressing or catching up with the trend. For the dream of a green economy to be possible, there must be some important developments in technology.

According to the US Energy Information Administration, World Energy Consumption in 2013 was $5.67 \times 1020$ joules. Hydrocarbons are responsible for providing more than $80 \%$ of energy worldwide. However, solar and wind energy constitute only $2 \%$ of global energy.

For a full transition to renewable energy, we need a 90 -fold increase in production over the next two decades. In this table, Canada, USA and Saudi Arabia, which are among the leading countries in the world, have the highest per capita energy demand today.

The new energy economy will have three levels of impact. These; Individuals, companies and governments. Looking at it, these three factors have a large direct impact on our lives. As we move towards this new economy, we must prepare ourselves for the changes that will arise from all three.

It has long been known that energy consumption is linked to economic growth. Since 2018, the demand for energy is actually due to climate change. The number of extremely hot or extremely cold days has increased, resulting in dependence on air conditioning. Therefore, we can say that climate change directly drives the economy.

New reforms in energy will regulate national economies for many countries with high solar and wind potential in the long run. Especially the end of fossil fuel use is very close; Conscious actions towards clean technology will benefit the country and its citizens environmentally. For this reason, the new energy economy is one of our main factors that we need to focus on.

Nowadays, we can think of startups as new superpowers. For this reason, we should head towards green energy together with these entrepreneurs. Because most of the interest of investors in green energy comes from these companies. We hope this trend continues and is supported.

The batteries produced annually by Tesla Gigafactory can now store three minutes of the annual electricity demand of the US. Storage of energy that can be provided by a 300-pound barrel requires 20,000 kilos of Tesla batteries. However, the interest shown by companies such as Tesla has led many investors and entrepreneurs to consider capitalist energy companies. This change has led to the emergence of many innovative energy solutions such as energy storage facilities and artificial intelligence powered microgrids. The journey to the green economy is still long. As individuals begin to embrace green energy, it is inevitable for companies to eventually follow the same path (Zahide Kaplan, 2020).

\section{Lighting Control Systems}

From an economic point of view, the increase in the types and number of fixtures used in lighting systems has made lighting control very difficult. Lighting control systems are used to facilitate the control of lighting devices and to make the most efficient use of lighting (Uyanik, M., Saribas, N., 2005).

The intended use of lighting control systems can be grouped under four main headings.

1. Efficiency

2. Energy Saving

3. Aesthetics

4. Flexibility

The most important benefit of lighting control is energy saving. Lighting control can save $30 \%$ in energy consumption and $10 \%$ in operating costs. A comfortable working environment is created with a correctly selected 
and implemented lighting control system. In addition, efficiency of the employees will increase with an appropriate lighting control (IEA Task 21, 2020).

In areas such as meeting rooms, design offices, textile workshops, factories, lighting control is very important for the highest level of work efficiency. With a well-programmed lighting automation system, it is possible to provide the highest level of work efficiency with the most suitable light level according to the working hours, the location of daylight and the nature of the work performed in such work areas. Lighting automation systems, sudden lighting programs according to the function by making changes in a very short time, it also eliminates the loss of time due to lighting adjustments.

Thanks to the dimmer units used in lighting automation systems, it is possible to save energy and extend the lifetime of the light sources as the lighting is reduced.

Light sensors to make maximum use of daylight, motion detectors to prevent energy consumption in areas where no one is available, astrological time clocks are integrated into the lighting automation system in order to be able to economically program environmental lighting to regulate lighting control according to working hours and environmental lighting. can be saved. In addition, energy savings can be achieved by automatically activating different lighting programs for times when electricity is expensive or inexpensive (Zhang, L., Yu, Y., Ma, H., Zhang, Y., Cao, P., 2018).

In places where there are no regular working hours and the lamps are left open when not in use, significant energy savings are achieved by controlling the lighting with motion sensors. With this method; Energy savings reaching $20 \%$ in open offices, $60 \%$ in personal offices, $70 \%$ in toilets, $40 \%$ in warehouses, $50 \%$ in classrooms and $65 \%$ in toilets in hotel rooms can be achieved (Cziker, A., Chindris, M., Miron, A., 2007).

A well-designed and daylighting lighting system saves $30 \%$ of lighting energy during the bright hours of the day. However, with the application of the saving methods mentioned below, this rate can reach $70 \%$.

- Application of time clock to the system and use of lighting only when necessary with access control systems.

- Use of motion detectors in areas with low personnel density.

- System dimmers working in harmony with daylight with the use of light level sensors.

- The light control system, when energy use reaches peak values, shuts down or diminishes insignificant areas (Lighting Controls Association, 2020).

\section{Calculation of Office Lighting}

\subsection{Lighting Account}

Various data and calculations are used for correct lighting. (Cao, C., Zhu, X, 2018) The tables given to you here are in the form of sampling. With these data, you can make more specific applications. Illumination calculations and factors of a place are explained step by step below (Cziker, A., Chindris, M., Miron, A.,2007).

\subsection{Reflection Coefficients of Important Substances}

In the table below, the reflection coefficients of some materials according to their color status are given. You can use these coefficients in the calculation.

\begin{tabular}{|l|c|l|c|}
\hline Material & $\boldsymbol{\%}$ & Wall Paints & $\%$ \\
\hline Dark & $0,10-0,20$ & Oak Light Color & $0,25-0,35$ \\
\hline Brown & $0,60-0,70$ & Chipboard Cream Color & $0,50-0,60$ \\
\hline Light yellow & $0,45-0,55$ & Plaster & 0,90 \\
\hline Light green & $0,30-0,50$ & Anodized Aluminum & 0,85 \\
\hline Light red & $0,35-0,45$ & Concrete & $0,10-0,50$ \\
\hline Sky blue & $0,70-0,90$ & Glass-Silver-Moon & $0,85-0,90$ \\
\hline White & $0,45-0,55$ & Granite & $0,20-0,25$ \\
\hline Pink & $0,40-0,60$ & White Marble & $0,60-0,65$ \\
\hline Light grey & $0,20-0,30$ & Lime whitewash & $0,40-0,45$ \\
\hline
\end{tabular}

Table 1. Reflection Coefficients of Some Materials and Wall Colors 


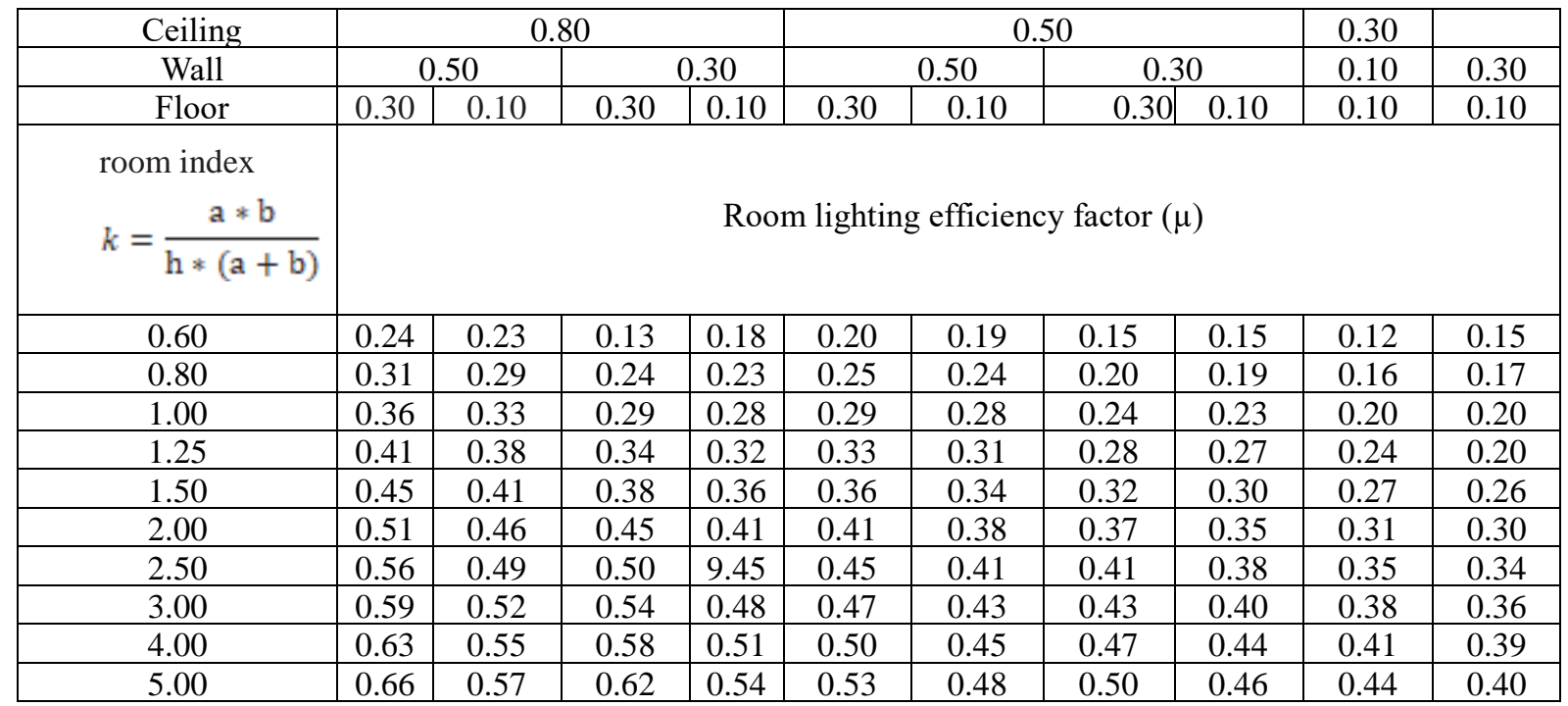

Table 2. Room Lighting Efficiency According to $k$ Values $\mu$

\subsection{Lighting Account Formulas}

$\mathrm{k}=$ room index

$\mathrm{a}=$ short edge length of the room

$\mathrm{b}=$ long edge of the room

$\mathrm{H}=$ height between armature and working surface

$$
k=\frac{a * b}{H *(a+b)}
$$

Using these values, the room index $\mathrm{k}$ value is calculated. When each luminaire is installed in place, the lamp is usually 20 to $60 \mathrm{~cm}$ below the ceiling. B type luminaires do not have a distance, but for example for chandeliers, rod length can be taken as $60 \mathrm{~cm}$. The working plane is generally considered to be $70-80 \mathrm{~cm}$ from the table length. In the sitting plane, 50 - $60 \mathrm{~cm}$ can be considered (Görgülü, S., Ekren, N., 2013).

\section{Practical Application of Fuzzy Technologies}

When both input and output are used with membership functions, conventional expressions between them are drawn up in this form: If (input UF x), then (output UF y). For example, "if the color is too dark, then the cost of success is very low". In the general approach, the model can have more than one input parameter and must be combined with the AND, OR, NO .T (Zadeh, Lotfi A., 1994). The parameters and rules are unstable, they can be changed under different conditions, which increases the model's usability. In the fuzzy process, each rule is evaluated to determine the output, and in the end the Fuzzy Inference System is the average of all outputs "Figure 4." In this way, each design work is done with a quantity that indicates that it is ultimately successful in terms of time and quality. This value is in the range [0 100] "Figure 3." When the process is complete, a list is created and can be used for visualization. It is possible to implement the model based on the values given in "Table 2".

The MATLAB program has developed a logical system with 3-inputs "Figure 1." 1 output "Figure 2." type and a fuzzy logic with 18 conditional constraints.

Input settings:

1) "Ceiling"

2) "Wall "

3) "Floor"

The output parameter is one: Value. 


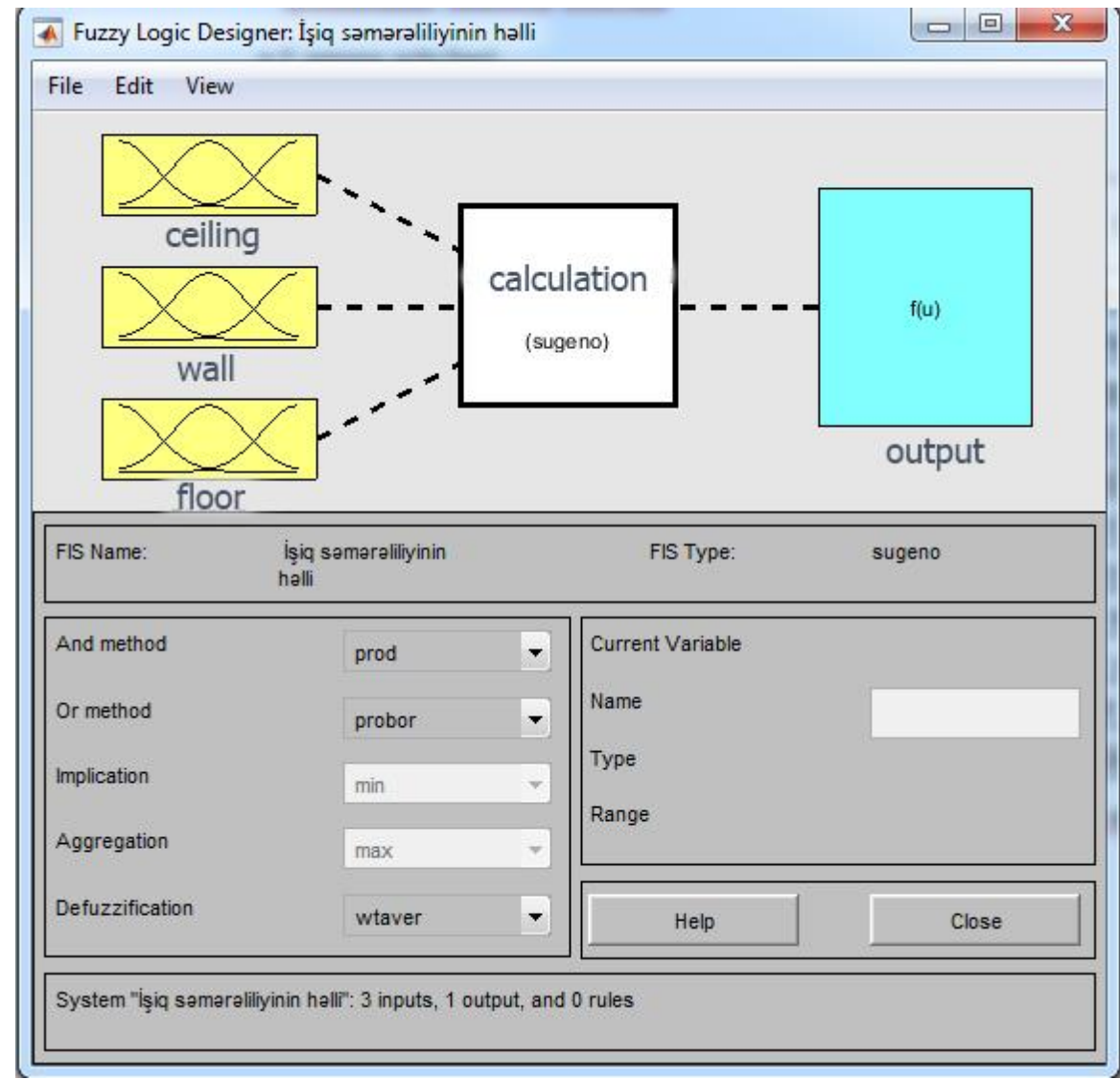

Figure 1. Input FIS-Editor Window

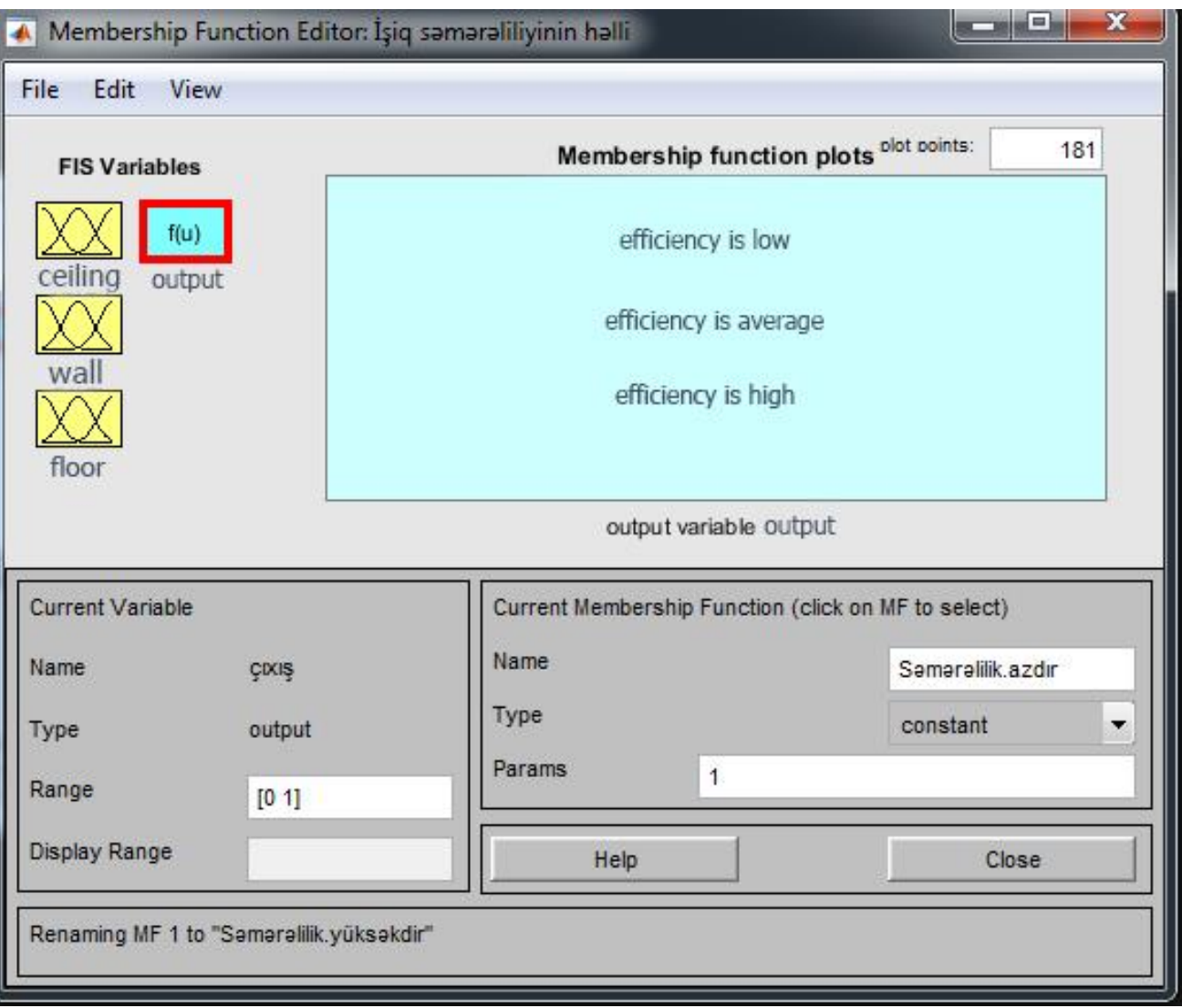

Figure 2. Output FIS-Editor Window 


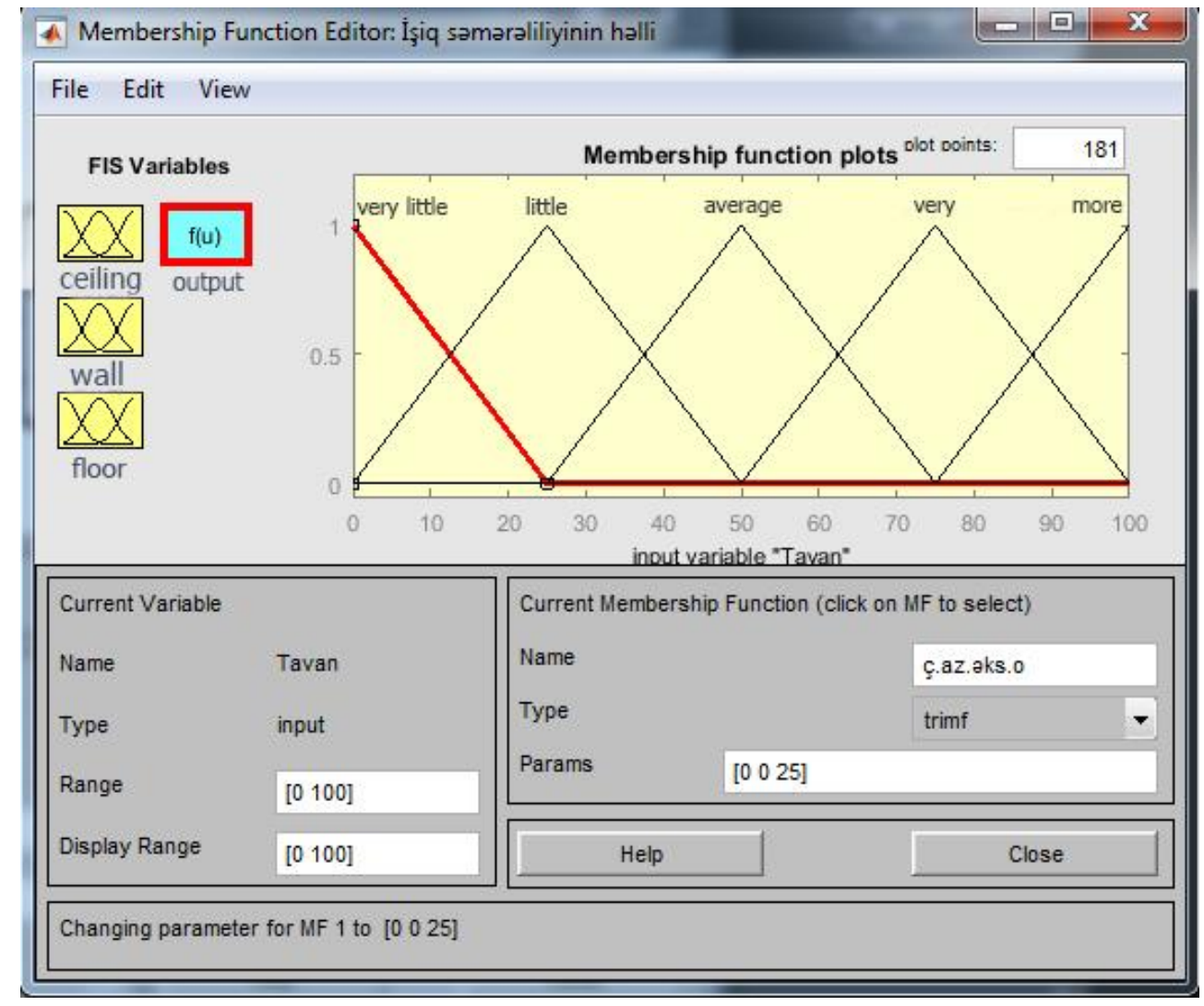

Figure 3. For the Application of Criteria Fuzzy Member Functions Edit Window

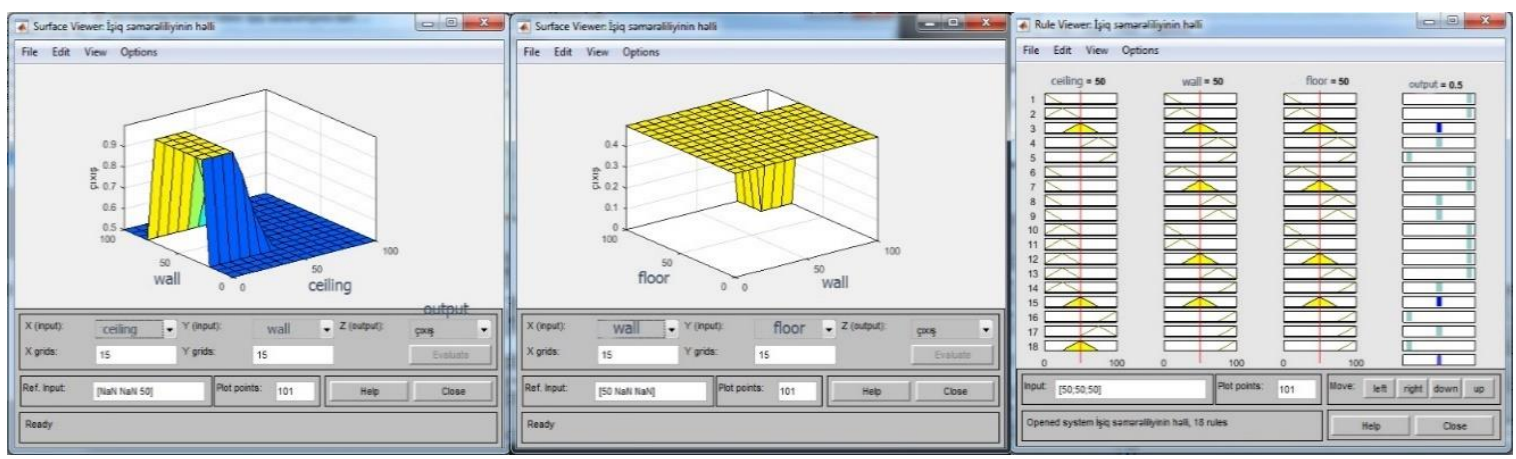

Figure 4. The Window of Fuzzy Rules

\section{Conclusion}

The application and innovation of energy efficient methods is a challenge for everyone. By reducing light scattering, higher levels of light production can be achieved without an increase in energy levels. Particular attention should be paid to energy saving with a clever combination of daylight and artificial light. When choosing lamp types, it should be noted that the efficiency factor has the highest efficiency classification and thus increases the level of high energy distribution with low energy levels. Developments in LED lighting technology need to be closely followed. Thus, it is recommended that all light reflection rates of colors be calculated based on a fuzzy logic model.

\section{References}

- $\quad$ Ağan, Y., LED Teknolojisi İle Aydınlatma Sanatı, İnşaat Dünyası Dergisi, Ekim 2005.

- Cao, C., Zhu, X.: Energy Management using Optimal Fuzzy Logic Control in Wireless Sensor Network. International Journal of Online and Biomedical Engineering 14(9), 35-52 (2018).

- Çolak, N., Hareket Sensörleri ile Aydınlatmanın Kontrolü, 3e Electrotech Dergisi, Sayı 105, Şubat 2003

- Cziker, A., Chindris, M., Miron, A.: Fuzzy Controller for Indoor Lighting System with Daylighting Contribution. In: ELECO'2007 5th International Conference on Electrical and Electronics Engineering. Turkey, (2007). 
- Cziker, A., Chindris, M., Miron, A: Implementation of Fuzzy Logic in Daylighting Control. In: 11th International Conference on Intelligent Engineering Systems, pp. 195-200. INES, (2007).

- Daylighting Control, Design and Application Guide, https://www.legrand.us//media/brands/wattstopper/resources/application-guide/ws-appguide-daylightingcontrol.ashx, last accessed 2020/04/30.

- Görgülü, S., Ekren, N.: Energy Saving in Lighting System with Fuzzy Logic Controller Which Uses LightPipe and Dimmable Ballast. Energy and Buildings 61, 172-176 (2013).

- IEA Task 21, Application Guide for Daylight Responsive Lighting Control, https://www.ieashc.org/Data/Sites/1/publications/8-8-1\%20Application\%20Guide.pdf, last accessed 2020/04/30.

- Lighting Controls Association, Introduction to Lighting Automation, http://lightingcontrolsassociation.org/2005/02/14/introduction-to-lighting-automation-for-the-home/, last accessed 2020/04/30.

- $\quad$ Rea, M.S.: IESNA Lighting Handbook. 9th edn. Illuminating Engineering (2000).

- Türk Mühendis ve Mimar Odaları Birliği, Enerjinin Etkin ve Verimli Kullanılmasının Ana Hatları, Şubat 2005 , s. 21-22.

- Uyanık, M., Sarıbaş, N., Aydınlatmada Enerji Verimliliği - Balast İlişkisi, 3e Electrotech Dergisi, Sayı 129, Şubat 2005.

- Zadeh, Lotfi A.,: Fuzzy Logic, Neural Networks, and Soft Computing, Communications of the ACM(37), 7784(1994).

- Zahide Kaplan: Yeni Enerji Ekonomisi Hakkında Bilmeniz Gereken Her Şey, elektrikport.com (2020).

- Zhang, L., Yu, Y., Ma, H., Zhang, Y., Cao, P.: Design of Photovoltaic Power Supply MPPT Circuit for WSN Node Based on Current Observation. International Journal of Online Engineering 14(7), 45-61 (2018). 